Bond University

Research Repository

\title{
Snatch trajectory of elite level girevoy (Kettlebell) sport athletes and its implications to strength and conditioning coaching
}

Ross, James A.; Wilson, Cameron J.; Keogh, Justin W L; Ho, Kuok Wai; Lorenzen, Christian

Published in:

International Journal of Sports Science and Coaching

DOI:

10.1260/1747-9541.10.2-3.439

Link to output in Bond University research repository.

Recommended citation(APA):

Ross, J. A., Wilson, C. J., Keogh, J. W. L., Ho, K. W., \& Lorenzen, C. (2015). Snatch trajectory of elite level girevoy (Kettlebell) sport athletes and its implications to strength and conditioning coaching. International Journal of Sports Science and Coaching, 10(2-3), 439-452. https://doi.org/10.1260/1747-9541.10.2-3.439

\section{General rights}

Copyright and moral rights for the publications made accessible in the public portal are retained by the authors and/or other copyright owners and it is a condition of accessing publications that users recognise and abide by the legal requirements associated with these rights.

For more information, or if you believe that this document breaches copyright, please contact the Bond University research repository coordinator. 
1 Snatch Trajectory of Elite Level Girevoy (Kettlebell) Sport Athletes and its Implications to Strength and Conditioning Coaching

James A. Ross ${ }^{1}$, Cameron J. Wilson ${ }^{1}$, Justin W.L. Keogh ${ }^{3}{ }^{4}$, Kuok Wai Hoํ․ and Christian Lorenzen ${ }^{1}$.

${ }^{1}$ School of Exercise Science, ACU, Melbourne, Australia

Postal address: 115 Victoria Parade, Fitzroy VIC 3065

${ }^{2}$ Faculty of Health Sciences and Medicine, Bond University, Gold Coast, Australia

Postal address: 14 University Drive, Robina QLD 4226

$9 \quad{ }^{3}$ Sports Performance Research Institute New Zealand, AUT University, Auckland, New Zealand

${ }^{4}$ Cluster for Health Improvement, Faculty of Science, Health, Education and Engineering, University of the Sunshine Coast 
3 Snatch Trajectory of Elite Level Girevoy (Kettlebell) Sport Athletes and its Implications 4 to Strength and Conditioning Coaching

5

6

7

8

9

10

11

12

13

14

15

16

17

18

19

20

21

22

23

24

25 


\section{Abstract}

2 Girevoy sport (GS) has developed only recently in the West, resulting in a paucity of

3 English scientific literature available. The aim was to document kettlebell trajectory of

4 GS athletes performing the kettlebell snatch. Four elite GS athletes (age $=29-47$ years,

5 body mass $=68.3-108.1 \mathrm{~kg}$, height $1.72-1.89 \mathrm{~m}$ ) completed one set of 16 repetitions

6 with a $32.1 \mathrm{~kg}$ kettlebell. Trajectory was captured with the VICON motion analysis

7 system $(250 \mathrm{~Hz})$ and analysed with VICON Nexus (1.7.1). The kettlebell followed a ' $\mathrm{C}$ '

8 shape trajectory in the sagittal plane. Mean peak velocity in the upwards phase was

$94.03 \pm 0.20 \mathrm{~m} \mathrm{~s}^{-1}$, compared to $3.70 \pm 0.30 \mathrm{~m} \mathrm{~s}^{-1}$ during the downwards phase, and

10 mean radial error across the sagittal and frontal planes was $0.022 \pm 0.006 \mathrm{~m}$. Low error

11 in the movement suggests consistent trajectory is important to reduce extraneous

12 movement and improve efficiency. While the kettlebell snatch and swing both require

13 large anterior-posterior motion, the snatch requires the kettlebell to be held stationary

14 overhead. Therefore, a different coaching application is required to that of a barbell

15 snatch.

16 Key Words: Kettlebell, Resistance Training, Snatch 


\section{INTRODUCTION}

2 Kettlebell exercise was initially seen at the end of the $17^{\text {th }}$ century in Russia, where

3 strongmen used $16 \mathrm{~kg}, 32 \mathrm{~kg}$ and $48 \mathrm{~kg}$ kettlebells to demonstrate feats of strength at

4 fairs, festivals and circuses [1, 2]. The first kettlebell sport, or 'Girevoy sport' (GS)

5 competition was held in 1948 and fourteen years later, GS was included into the

6 national sports of Russia [1]. Over the past ten years, kettlebell training has become

7 increasingly popular as a form of resistance training for athletes and members of the

8 general population, coinciding with increased participation in GS competition. Whilst the

9 versatility of kettlebells allows the performance of many exercises; swings, jerks, clean

10 and jerks, and snatches are some of the most commonly performed kettlebell

11 movements.

12 The snatch is typically performed with a barbell in Olympic weightlifting events, although

13 dumbbell and kettlebell versions are becoming more popular. The kettlebell snatch is

14 performed in a biathlon or as a standalone event in GS competitions. The competition

15 takes place on a weightlifting platform and has a time limit of ten minutes per set. The

16 biathlon is scored as the total number of repetitions performed from two exercises: the

17 jerk followed by the snatch, each of ten minutes duration, with at least an hour between

18 exercises. The snatch is performed with one hand change permitted per set and is

19 considered the most technical event in GS [1]. Elite individuals perform the kettlebell

20 snatch with a $32 \mathrm{~kg}$ kettlebell during the ten minute competition, with the current

21 absolute world record standing at 238 snatches. 
1 It has been suggested that kettlebell training is a useful mode of training to improve

2 aerobic fitness [3-5],vertical jump [6-9] and back squat performance [7, 9]. Previous

3 research utilising a $32 \mathrm{~kg}$ 2-handed kettlebell swing demonstrated similar power outputs

4 and a larger impulse, compared to the jump squat with 40\% 1RM [8]. A training study

5 comparing the chronic effects of kettlebell swings and jump squats was reported to

6 significantly improve vertical jump and back squat 1RM. However, the kettlebell group

7 had a smaller improvement in the vertical jump, yet larger improvement in back squat

8 performance [7]. Of the two interventions that investigated the effects of kettlebell

9 training on the cardiorespiratory system, only one found improvements. It is possible

10 that the reason for the lack of improvement was due to the low training dosage of 10-15

11 minutes three times a week with $70 \%$ adherence [10]. In contrast, $30-45$ minutes of

12 training twice a week, using a combination of kettlebell exercises including the snatch,

13 was found to improve VO2peak by $13.8 \%$ during a progressive kettlebell snatch set [5].

15 Generally, only qualitative descriptions of the kettlebell snatch during elite performance

16 are available. The International Kettlebell Sport \& Fitness Academy has described the

17 snatch as comprising six components [11]. As seen in Figure 1, the start and finish are

18 referred to as "fixation". This is where the kettlebell is locked out overhead. The three

19 components of the downwards phase include: the drop, re-gripping, and back swing,

20 while the upwards phase involves the forward swing, acceleration pull, and hand

21 insertion (refer to Figure 1). 
1 Figure 1 about here

3 Figure 2 about here

5 Figure 2, point 1 represents fixation. In this position, the handle of the kettlebell rests

6 diagonally across the palm and the ball rests on the back of the wrist and forearm [11].

7 The drop is initiated by a counter movement of the torso away from the kettlebell. At

8 approximately the same time, the shoulder begins to extend, and the elbow supinates

9 and flexes [1, 11]. Between the 'drop' and the 'back swing' the handle is repositioned

10 (re-gripped) from the palm to the fingers [11]. This portion of the downwards trajectory is

11 indicated at approximately Figure 2, point 2. At the start of the back swing the knees are

12 slightly flexed and the torso remains upright, until the kettlebell passes between the

13 legs, whereby the hips flex and the knees extend (finishing at Figure 2, point 3). The

14 forwards swing phase consists of the kettlebell moving forward between the legs via hip

15 extension and knee flexion. The acceleration pull (approximately Figure 2, point 4)

16 begins as the kettlebell passes the knees. This is the most powerful motion in the

17 snatch, and involves knee and hip extension, ipsilateral torso rotation and elbow flexion

18 [11]. It ends when the kettlebell is once again re-gripped (hand insertion). During the

19 hand insertion phase, the elbow is extended and the torso rotates contralaterally [11].

20 This rotates the kettlebell, moving the handle from the fingers to the palm, bringing it

21 into contact with the wrist and forearm [11]. The kettlebell comes to rest in the overhead

22 position whilst in fixation, and the process is then repeated (see Figure 1). It has been 
1 suggested that in the upwards and downwards phases the kettlebell follows somewhat

2 different trajectories [1]. To our knowledge, only one study has examined the technique

3 of the kettlebell snatch [12], reporting that novice participants extend the hips, knees

4 and ankles simultaneously, and swing the kettlebell through the sagittal plane. The

5 kettlebell snatch was further described to have rapid muscle activation-relaxation

6 cycles, producing relatively large posterior shear forces on the spine [12].

7 This proposed trajectory of the snatch performed with a kettlebell appears quite different

8 to that of the snatch performed with barbells or dumbbells. The barbell snatch and

9 power snatch has been shown to follow an 'S' or reverse ' $S$ ' shaped trajectory,

10 characterised by an initial small displacement of the barbell rearwards, then forwards

11 and rearwards again $[13,14]$. This type of trajectory allows the weightlifter to move

12 through the first pull and transition phase, and to adopt the power position prior to the

13 second pull. The power position may allow for the generation of very large power

14 outputs during the second pull [15]. Elite weightlifters were found to have an anterior

15 posterior range of $-0.096 \pm 0.07 \mathrm{~m}$ during successful barbell snatch attempts. In contrast,

16 the trajectory of a dumbbell power snatch is displaced forwards then rearwards [16].

17 During competition, the barbell snatch is performed with a bilateral grip for one maximal

18 repetition. Conversely, the kettlebell snatch is performed unilaterally and traditionally

19 utilises multiple repetitions in competitions. The duration and technique used in the

20 upwards and downwards phases may both be of importance. Additionally, the

21 kettlebells displaced centre of mass sits below the wrist. This makes it much harder to

22 safely fail a single maximal lift of a kettlebell snatch, compared to that of a barbell or

23 dumbbell snatch. This may suggest the kettlebell snatch is better suited to higher 
1 repetitions than the barbell snatch and as such may be a better tool for increasing

2 energy expenditure and developing aerobic and anaerobic conditioning.

4 In comparison to the barbell snatch, the unilateral nature of the kettlebell snatch allows

5 for greater degrees of freedom, which may result in a larger choice of techniques.

6 However, the unique shape of the kettlebell may necessitate a modified approach to

7 training and technique, in contrast to that of a barbell. The material and body of

8 knowledge available to coaches regarding kettlebell exercises for training purposes is

9 limited. The present study aimed to investigate the kettlebell trajectory of elite kettlebell

10 lifters during the snatch. This information is especially important for coaches and

11 strength and conditioning specialists looking to prescribe higher repetition snatch

12 movements for their athletes. As a training tool, the kettlebell snatch may be better

13 suited to higher repetitions. Comparatively, this may require different applications to that

14 of the barbell snatch, traditionally utilising one repetition in competition.

\section{METHOD}

\section{Testing Procedures}

18 Four elite participants performed 16 repetitions over one minute with one $32 \mathrm{~kg}$

19 kettlebell. Repetitions 2-16 were compared to help determine the variation in the

20 trajectory as these repetitions all had a downward phase preceding the upward.

21 Kettlebell trajectory was captured with the VICON Motion Analysis System $(250 \mathrm{~Hz})$ and 
1 analysed with VICON Nexus (1.7.1). The cadence of 16 repetitions per minute was

2 selected based on similar cadences sustained during either training or competition.

\section{Participants}

4 Four elite kettlebell sport athletes (originating in Russia or Kyrgyzstan), who had all won

5 at least one world championship in biathlon (jerk and snatch) and/or held past or current

6 world records in the snatch, were recruited. In their most recent competition, which

7 occurred within 12 months of data collection, all lifters performed between $80-100 \%$ of

8 the current world record number of lifts with a 32kg kettlebell for their respective weight

9 categories. All participants held the rank of 'Master of Sport International Class' or

10 'Honored Master of Sport', (as issued by the Ministry of Sports of Russia, or the USSR

11 State Committee for Physical Culture and Sport). The four participants had the following

12 characteristics: age $=29-47 \mathrm{yr}$, body mass $=68.3-108.1 \mathrm{~kg}$, and height $=1.72-1.89 \mathrm{~m}$.

13 This study was approved by the Institutional Review Board. Informed consent was

14 given, in the presence of a translator if required.

\section{Procedures}

16 Six VICON infrared cameras were placed around a weightlifting platform in a position to

17 capture three dimensional motion of the kettlebell during the snatch. The infrared

18 cameras captured the movement of reflective markers placed on the kettlebell. The

19 system was calibrated dynamically by waving an L-wand with five reflective markers in

20 the area that the kettlebell would pass through, in accordance to the manufacturer's

21 instructions. This was repeated until all cameras had an RMS error under $0.2 \%$ [17].

22 The point of origin was then set in the middle of the platform, to calibrate the cameras 
1 positions. A professional-grade kettlebell (Iron Edge, Australia), with a mass of $32.1 \mathrm{~kg}$

2 was used as its dimensions are the standard requirement for kettlebell sport. Two

3 markers (14 $\mathrm{mm} \times 12.5 \mathrm{~mm}$ in diameter) were placed on the kettlebell at the base of

4 each handle to avoid contact with the athlete and to ensure consistent position.

5 Participants were required to perform a warm-up they would typically perform prior to

6 performing the kettlebell snatch. Chalk, sand paper and a spray bottle were provided to

7 ensure that the handle was prepared to their individual lifting requirements. After the

8 marker set had been placed, each lifter stood on a platform and performed one set of

9 snatches for 16 repetitions over 1 minute with their self-selected hand. This pace was

10 selected as it was the competition pace for one or more of the athletes, was attainable

11 by novice and intermediate athletes (albeit with lighter loads), and commonly performed

12 in training and competition. An analogue clock was placed in view to allow consistent

13 pace.

14 Kettlebell trajectory was subsequently determined by attaining the midpoint of the two

15 markers. After each trial had been performed the markers were manually labelled using

16 VICON Nexus software. A frame-by-frame review of each trial was undertaken to

17 ensure there was minimal error caused by unlabelled markers. After this review took

18 place a Woltering spline filter was applied to fill any gaps (less than 20 frames) in the

19 trajectories [18]. These gaps in the trajectories were calculated by the markers past

20 trajectory, velocity and acceleration.

21 Time displacement data was used to determine the trajectory and velocity in three

22 dimensions of motion. For ease of interpretation resultant velocity was used. Four

23 points of each repetition of the kettlebell trajectory were analysed: 1) fixation; 2) 
1 midpoint of the downwards phase; 3 ) end of the back swing; and 4) midpoint of the

2 upwards phase (see Figure 2).

4 These four points were identified the moment the kettlebells trajectory changed from an

5 anterior to posterior direction, or vice versa. The mean position from all 15 repetitions at

6 these four points was the goal position. These four points were used as a reference to

7 determine the error in one and two dimensions. The absolute error ( $A E$, including

8 vertical error, anterior-posterior error and medio-lateral error) illustrated the distance in

9 metres from the goal in one dimension [19]. The radial error (RE, including sagittal

10 plane error and frontal plane error) signified the distance in metres from the goal in two

11 dimensions [19]. The RE was calculated by using the following formula:

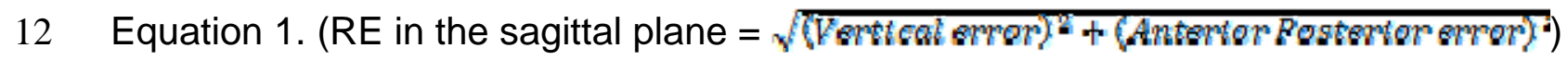

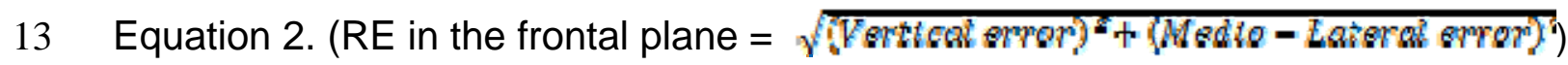

15 The anterior-posterior (AP), medio-lateral (ML) and vertical displacements were

16 calculated from the end of the back swing to the midpoint of the trajectory for AP and

$17 \mathrm{ML}$, and to fixation for the vertical displacement range. Comparisons in the lifters'

18 trajectories were also made using an anterior-posterior to vertical ratio (APV), and

19 medio-lateral to vertical (MLV) ratio. The end of the back swing to fixation mean

20 displacement range was used to determine the vertical portions of the ratios.

\section{Statistical Analyses}


1 Data has been presented as means and standard deviations unless stated otherwise.

2 Descriptive statistics were used to determine the amount of kettlebell AP, ML motion

3 and variation for each lifter. Effect size (ES) and paired t-tests with two tails were used

4 to compare the midpoint of the upwards and downwards phases for each repetition. The

5 magnitude of the effect was considered trivial ES $<0.2$, small ES 0.2-0.6, moderate 0.6-

6 1.2, large ES 1.2-2.0, very large ES 2.0-4.0 and extremely large ES > 4.0 [20]. The AE

7 and RE for repetitions 2-16 were calculated. The first repetition was ignored because it

8 started from the ground and not in fixation. The variation was determined at the same

9 four points, listed above. AE was calculated in $A P, M L$ and vertical planes of motion. RE

10 was calculated in the sagittal and frontal planes.

\section{RESULTS}

\section{Trajectory}

14 In the sagittal plane, the trajectory of the kettlebell snatch followed a C-path for all

15 participants through the upwards and downwards phases (Figure 3). Figure 3 illustrates

16 the kettlebell sagittal plane trajectory for the four subjects, whilst Figure 4 represents the

17 kettlebell trajectory in the frontal plane of motion.

Figure 3 about here 


\section{Ratios and displacement}

3 Table 1 illustrates the kettlebell displacement ranges and ratios. The APV and MLV

4 ratios indicate that the C-path followed a larger radius during the upwards than

5 downwards phase for all participants. Participants B, C, and D had a relatively smaller

6 MLV ratio ranging from $0.05-0.13$ for both phases compared to participant $A$, who had a

7 relatively larger MLV ratio of $0.31 \pm 0.01$ and $0.26 \pm 0.02$ for the upwards and

8 downwards phases, respectively.

$9 \quad$ Table 1 about here

11 Table 2 shows the AP, ML and vertical displacement ranges between the upwards and

12 downwards phases. The downwards phase represents the smallest arc, compared to

13 the upwards phase. The range between the upwards and downwards phases was

14 largest in the AP, compared to the ML differences in all lifters.

16 Table 2 about here

18 Velocity

19 Participants' peak kettlebell resultant velocity ranged from moderate to extremely large

20 ES difference, whereby the upwards phase was faster than the downwards phase for all 
1 lifters, except lifter A (see Table 3). Figure 5 shows the typical velocity of the kettlebell

2 as it moved from the downwards phase to the upwards phase. The two peaks in velocity

3 occurred approximately in the re-gripping phase and during the acceleration pull. The

4 two noted times in which velocity reached zero were at fixation, and momentarily

5 between the back and forwards swing.

$7 \quad$ Figure 5 about here

$9 \quad$ Table 3 about here

\section{Movement Variability}

12 Table 3 shows AE, RE and displacement range for the three dimensions for each

13 participant. The AE and the RE indicate that the kettlebell trajectory was highly

14 consistent at each of the four points for all four participants.

16 Table 4 about here 
1 Three dimensional motion analysis was used in this study to document kettlebell snatch

2 kinematics performed by elite kettlebell athletes. The main findings were that despite

3 some differences between the four athletes, significant commonalities emerged: 1)

4 there was a ' $\mathrm{C}$ ' shape trajectory during the downwards and upwards phases of the

5 snatch; 2) the ' $C$ ' shape followed a narrower trajectory during the downwards phase;

6 and 3) the resultant velocity time graph resembled an ' $M$ ' shape.

7 One marked similarity was the narrow ' $C$ ' shape trajectory on the way down and a wider

8 ' $C$ ' shape on the way up. The smaller radius on the way down may be due to several

9 reasons. During the initiation of the downwards phase it was noticed that all athletes

10 moved their bodies away from the kettlebell. This allowed for the kettlebell to fall as

11 closely as possible to the base of support. Following the initial counter movement the

12 athlete flexes and supinates the elbow $[1,11]$. The supination of the elbow may help to

13 reduce the movement of the kettlebell through the AP plane and minimise grip stress

14 (and subsequent fatigue) during the transition into the re-gripping phase. The flexion of

15 the elbow may also minimise the AP movement of the kettlebell, thereby again placing

16 the kettlebell as close to the base of support as possible. The large radius from the

17 forwards swing to the start of the acceleration pull may help to minimise the centripetal

18 force acting on the grip. Following the acceleration pull, the hand insertion phase guides

19 the kettlebell onto the back of the wrist. The grip must relax during this phase to help

20 facilitate a smooth transition into fixation. Reducing the stress on the grip may help to

21 prolong performance as anecdotally grip endurance is considered the weakest link in

22 elite GS athletes. Paying particular attention to the hand insertion will also help to

23 reduce the potential for the kettlebell to have heavy contact upon the forearm, and 
1 therefore reduce the risk of musculoskeletal injury to the distal forearm. Strength and

2 conditioning coaches need to be aware of this before their athletes progress the

3 kettlebell snatch.

4 Movement was remarkably consistent for all athletes in the frontal and sagittal planes.

5 This is most likely to minimise energy expenditure and therefore fatigue over the ten

6 minute event. The most consistent of the four points was the fixation phase which had a

7 RE range of $0.008 \pm 0.006 \mathrm{~m}$ and $0.023 \pm 0.016 \mathrm{~m}$, in both sagittal and frontal planes.

8 This would suggest that a consistent fixation phase is of the upmost importance. Low

9 endpoint variability is most useful to ensure that the mass of the kettlebell is over the

10 shoulder in all three planes. If this was not the case, greater energy and time would be

11 used fixating or locking out the kettlebell overhead. Within the limitations of the research

12 it can be concluded that elite kettlebell sport athletes maintain a consistent trajectory,

13 particularly at some of the key positions of the movement. Maintaining consistent

14 fixation may be key in increasing the reproducibility of the trajectory as it marks the start

15 and finish of the lift. The trajectory of the kettlebell for athletes $A$ and $C$ followed a

16 similar path during both the downwards and upwards phases in the sagittal plane, whilst

17 the vertical midpoints were at a relatively similar level for lifters A and C $(0.022 \pm 0.015$

$18 \mathrm{~m}$ and $0.034 \pm 0.020 \mathrm{~m}$ trajectory difference, respectively). In contrast, the trajectory for

19 athletes B and D were visibly separated and the vertical midpoint of the ' $C$ ' shape

20 occurred in different vertical positions in the upwards and downwards phases $(0.062 \pm$

$210.030 \mathrm{~m}$ and $0.094 \pm 0.028 \mathrm{~m}$, respectively) (Figure 3). These differences in trajectory

22 could be explained by: 1) greater trunk rotation in the acceleration pull phase; 2) the

23 degree of plantar flexion in the upwards or downwards phase; 3) a larger shift 
1 backwards during the downwards phase; 4) the position of the upper extremity; and 5)

2 possibly anthropometrical differences. Unfortunately, the present study only assessed

3 the motion of the kettlebell, however, future studies may be useful to better describe the

4 relationship between the kettlebell and lifters kinematics. Potentially, technique may

5 differ over the course of the ten minutes due to fatigue or changes in cadence, however,

6 these differences were beyond the scope of the present study.

8 Based on the kettlebell kinematics, it appears that different strategies were used to

9 prolong performance in the different lifters. Lifter A displayed the largest MLV range in

10 the upwards and downwards phases, which may produce fatigue in the contralateral

11 musculature to a greater extent. In novice athletes, the mean activation of the lower

12 erector spinae performing the kettlebell snatch with a sagittal plane trajectory was 54.2

$13 \pm 18.3$ and $61.3 \pm 16.3 \% \mathrm{MVC}$ for the ipsilateral and contralateral sides, respectively

14 [12]. Lifter A may increase the demands of the contralateral musculature further by

15 increasing the ML moment arm (which is reflected in his MLV ratio). This may increase

16 the requirements of the torso to resist or control lateral flexion to a greater extent, in an

17 effort to offset fatigue for the last five minutes. In doing so, they may possibly spare the

18 ipsilateral side for subsequent effort following the hand switch as it will become the

19 contralateral side at the five minute mark. Thus, having a larger MLV ratio trajectory

20 may be a strategy to help spread the loading across different muscle groups during the

21 left and right hand efforts. This strategy may be particularly useful during biathlon, as

22 athletes must perform the jerk, which predominantly takes place in the sagittal plane

23 one or two hours prior to the snatch, and may still be experiencing fatigue from this 
1 effort [3, 4]. Lifters B, C and D had much smaller MLV ratios compared to lifter A. The

2 dominant AP trajectory in lifters $B, C$ and $D$ suggests that their strategy requires

3 relatively symmetrical loading, resulting in less effort by a single muscle group, thus

4 prolonging performance. A sagittal plane dominant trajectory similar to lifters $B, C$ and $D$

5 may offer strength and conditioning coaches a technique with the greatest ease of

6 application. Conversely, lifter A's style may be useful in a GS setting, however it would

7 require a coach to monitor both sagittal and frontal planes of motion, with respect to the

8 kettlebell trajectory.

9 As previously stated, upward phase horizontal displacement of the kettlebell was

10 greater than the downward phase equivalent for all lifters, perhaps to reduce the

11 centripetal load on the fingers. Increasing kettlebell velocity may further increase the

12 centripetal stress on the fingers. Two peaks in velocity between the upwards and

13 downwards phases were observed across all lifters. The first peak occurred

14 approximately in the re-gripping phase, and the second generally in the acceleration pull

15 phase. Lifters B, C and D had slower peak velocities in the downwards phase, whereas

16 lifter A's peak velocity was greatest during the downwards phase. Reducing the velocity

17 on the downwards phase could help to reduce stress placed on the finger flexors,

18 however it could also increase the time needed to perform each repetition, which may

19 be counter-productive to the objective of the sport which is to perform as many

20 repetitions as possible in 10 minutes. Strength and conditioning coaches should be

21 aware that in addition to the obvious effect of altering the kettlebell mass, different

22 cadences and/or anthropometric factors may result in different kettlebell velocities.

23 Therefore, an increase in cadence may result in greater velocity in the downwards 
1 phase and a faster eccentric phase. This increase in repetition velocity may result in

2 greater grip and systemic fatigue, which may only be sustainable over shorter time

3 periods.

\section{Conclusion}

5 The kettlebell snatch trajectory of elite GS athletes follows a 'C' shaped path. There

6 were two differently shaped ' $C$ ' trajectories, one with a smaller radius on the downwards

7 phase, and the other a larger during the upwards phase. Kettlebell displacement

8 occurred predominantly in the sagittal plane, although varying and relatively smaller

9 amounts of horizontal displacement were recorded in the frontal plane. Within the

10 upwards and downwards phases, low movement variability appears an important factor,

11 particularly in the overhead fixation position. With the kettlebells potential large degrees

12 of freedom, individual athlete style may affect their trajectories.

13 Additionally, there were two peaks in velocity which occurred in the upwards and

14 downwards phases. This technique easily facilitates multiple repetitions due to its

15 cyclical upwards and downwards phases. This research has shown that the kettlebell

16 snatch can be performed with consistent kettlebell trajectories and velocities for 15

17 repetitions by elite GS athletes in a relatively unfatigued state.

\section{Practical application}

19 The kettlebell snatch may be a useful option as an alternative to high repetitions of the

20 barbell snatch, as it can be performed consistently. This may be particularly useful for

21 strength and conditioning coaches, wishing to program an explosive total body

22 movement such as the snatch for higher repetitions. Additionally, the unilateral and 
1 swinging nature of the kettlebell may provide a unique stimulus. Programming a snatch

2 for higher repetitions may increase the metabolic and grip demands [5]. These

3 components may also be important factors in sports that require a combination of

4 strength and endurance qualities. Grip strength is an important component of Judo

5 competition [21]. Grappling sports such as Judo, freestyle and Greco-Roman wrestling

6 typically involve tournament formats and a progressive increase in fatigue and grip

7 strength loss occurs with each bout during these tournaments [22-25]. The kettlebell

8 snatch may have potential application in these sports, as it may promote increased

9 levels of local muscular endurance. In contrast, the barbell snatch has been well

10 researched and is an effective stimulus for power adaptations [15]. Its trajectory follows

11 an 'S' shape which is predominantly vertical, allowing for positions which maximise

12 power output. Therefore, the barbell snatch would be most appropriately programmed

13 for lower repetitions, in contrast to the kettlebell snatch, which may be better suited to

14 higher repetitions. The kettlebell snatch has a cyclical component, as it contains an

15 upwards and downwards phase. Following a 'C' trajectory will help to prolong

16 performance and in turn training volume, which may allow for greater training outcomes.

17 Problems may arise if a lifter attempted to apply an ' $S$ ' trajectory to the kettlebell, which

18 may not be appropriate or attainable, and may cause the hand insertion and fixation

19 phases to occur too closely together (when the arm is vertical). This may lead to greater

20 impact upon the forearm, thus increasing the risk of injury. Evidently, kettlebell snatch

21 technique should not be taught in the same manner as the barbell snatch.

\section{Limitations}


1 The small sample size recruited is the major limitation within this research, however the

2 athletes involved are all elite within GS, making them of particular interest. Due to time

3 constraints and international travel stress, the lifters were unable to perform 10 minute

4 sets at a competition pace for this study. This would have offered an insight into their

5 trajectories in a fatigued state. A total of 16 repetitions were studied over one minute.

6 The number of repetitions performed was at competition pace for the two lighter lifters.

7 However, this was below competition pace for the two heavier lifters.

\section{Acknowledgments}

10 The authors would like to thank IKSFA (www.IKSFA.com), WKC

11 (www.worldkettlebellclub.com), Sergey Rudnev and the other athletes for taking part in

12 the research. No financial support was taken from these organizations. We would also

13 like to thank Dr. Brett O'Connell for his technical support.

14

15

16

17

18

19 


\section{References}

1. Tikhonov, V.F., Suhovey, A.V. and Leonov D.V., Fundamentals of Kettlebell Sport: teaching motor actions and methods of training: a manual, Soviet Sport, 2009.

2. Tsatsouline, P., Enter the Kettlebell!, Dragon Door Publications, Inc., St. Paul, MN., 2006.

3. Farrar, R.E., Mayhew, J.L. and Koch, A.J., Oxygen cost of kettlebell swings, Journal of Strength \& Conditioning Research, 2010, 24(4), 1034-1036.

4. Hulsey, C.R., Soto, D.T., Koch, A.J. and Mayhew, J.L., Comparison of kettlebell swings and treadmill running at equivalent rating of perceived exertion values, Journal of Strength \& Conditioning Research, 2012, 26(5), 1203-1207.

5. Beltz, N., Erbes, D., Porcari, J.P., Martinez, R., Doberstein, S. and Foster, C., Effects of kettlebell training on aerobic capacity, muscular strength, balance, flexibility, and body composition, Journal of Fitness Research, 2013, 2(2), 4-13.

6. Jay, K., Jakobsen, M. D., Sundstrup, E., Skotte, J. H., Jørgensen, M. B., Andersen, C. H., and Andersen, L. L., Effects of kettlebell training on postural coordination and jump performance: a randomized controlled trial, Journal of Strength \& Conditioning Research, 2013, 27(5), 1202-1209.

7. Lake, J.P. and M.A. Lauder, Kettlebell swing training improves maximal and explosive strength, Journal of Strength \& Conditioning Research, 2012, 26(8), 2228-2233.

8. Lake, J.P. and M.A. Lauder, Mechanical demands of kettlebell swing exercise, Journal of Strength \& Conditioning Research, 2012, 26(12), 3209-3216.

9. Otto III, W. H., Coburn, J. W., Brown, L. E., and Spiering, B. A., Effects of weightlifting vs. kettlebell training on vertical jump, strength, and body composition. Journal of Strength \& Conditioning Research, 2012. 26(5), 11991202.

10. Jay, K., Frisch, D., Hansen, K., Zebis, M. K., Andersen, C. H., Mortensen, O. S., and Andersen, L. L., Kettlebell training for musculoskeletal and cardiovascular health: a randomized controlled trial. Scandinavian journal of work, environment \& health, 2011. 37(3), 196-203.

11. Rudnev, S., Kettlebell sport coach manual, IKSFA, 2010.

12. McGill, S.M. and L.W. Marshall, Kettlebell swing, snatch, and bottoms-up carry: back and hip muscle activation, motion, and low back loads. Journal of Strength \& Conditioning Research, 2012. 26(1), 16-27.

13. Stone, M. H., O'Bryant, H. S., Williams, F. E., Johnson, R. L., and Pierce, K. C., Analysis of bar paths during the snatch in elite male weightlifters. Strength \& Conditioning Journal, 1998. 20(4), 30-38.

14. Winchester, J.B., J.M. Porter, and J.M. McBride, Changes in bar path kinematics and kinetics through use of summary feedback in power snatch training. Journal of Strength \& Conditioning Research, 2009. 23(2), 444-454.

15. Garhammer, J., A review of power output studies of Olympic and powerlifting: Methodology, performance prediction, and evaluation tests. Journal of Strength \& Conditioning Research, 1993. 7(2), 76-89. 
16. Lauder, M.A. and J.P. Lake, Biomechanical comparison of unilateral and bilateral power snatch lifts. Journal of Strength \& Conditioning Research, 2008. 22(3), 653-660.

17. Ho, K. W. L., Williams, M. D., Wilson, C. J., and Meehan, D. L., Using ThreeDimensional Kinematics to Identify Feedback for The Snatch: A Case Study. Journal of Strength \& Conditioning Research, 2011. 25(10), 2773-2780.

18. Woltring, H.J., A FORTRAN package for generalized, cross-validatory spline smoothing and differentiation. Advances in Engineering Software, 1986. 8(2), 104-113.

19. Magill, R., Motor Learning: Concepts and Applications, Boston, MA,WCB McGraw-Hill. 1998, 20-21.

20. Hopkins, W.G., Linear Models and Effect Magnitudes for Research, Clinical and Practical Applications. Sportscience, 2010, 49-57. http://www.sportsci.org/2010/wghlinmod.htm

21. Miarka, B., Panissa, V. L. G., Julio, U. F., Del Vecchio, F. B., Calmet, M., and Franchini, E., A., comparison of time-motion performance between age groups in judo matches. Journal of sports sciences, 2012. 30(9), 899-905.

22. Bonitch-Góngora, J. G., Bonitch-Domínguez, J. G., Padial, P., and Feriche, B., The effect of lactate concentration on the handgrip strength during judo bouts. Journal of Strength \& Conditioning Research, 2012. 26(7), 1863-1871.

23. Branco, B. H. M., Massuça, L. M., Andreato, L. V., Miarka, B., Monteiro, L., Marinho, B. F., and Fanchini, E., Association between the Rating Perceived Exertion, Heart Rate and Blood Lactate in Successive Judo Fights (Randori). Asian Journal of Sports Medicine, 2013. 4(2), 125-130.

24. Barbas, I., Fatouros, I. G., Douroudos, I. I., Chatzinikolaou, A., Michailidis, Y., Draganidis, D., and Theodorou, A. A., Physiological and performance adaptations of elite Greco-Roman wrestlers during a one-day tournament. European journal of applied physiology, 2011. 111(7), 1421-1436.

25. Kraemer, W. J., Fry, A. C., Rubin, M. R., Triplett-McBride, T., Gordon, S. E., Koziris, L. P., and Newton, R. U., Physiological and performance responses to tournament wrestling. Medicine and science in sports and exercise, 2001. 33(8), 1367-1378.

(1)

.



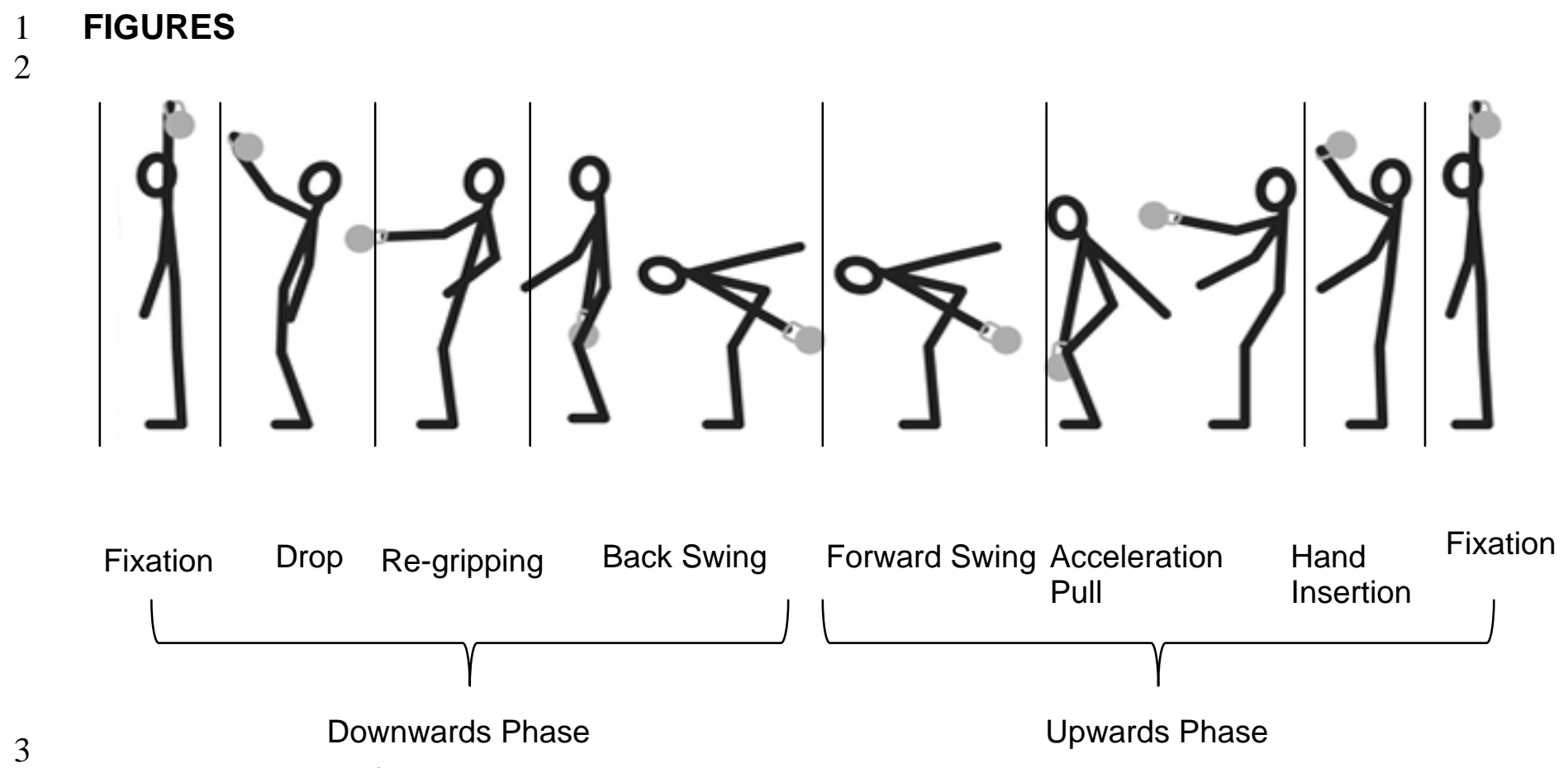

Downwards Phase
4 Figure 1. Phases of the kettlebell snatch.

5
6
7
8
9

10

11

12

13

14

15

16

17

18

19

20

21

22

23

24

25

26

27

28

29

30 


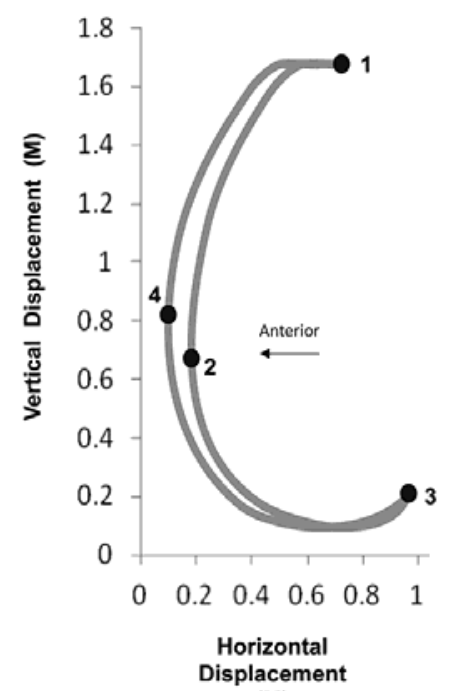

(M)

1

2

3

4

5

6

7

8

9

10

11

12

13

14

15

16

17

18

19

20

21

22

23

24

25

26

27

28

Figure 2. An example of the four points of error in the kettlebell snatch. 
A

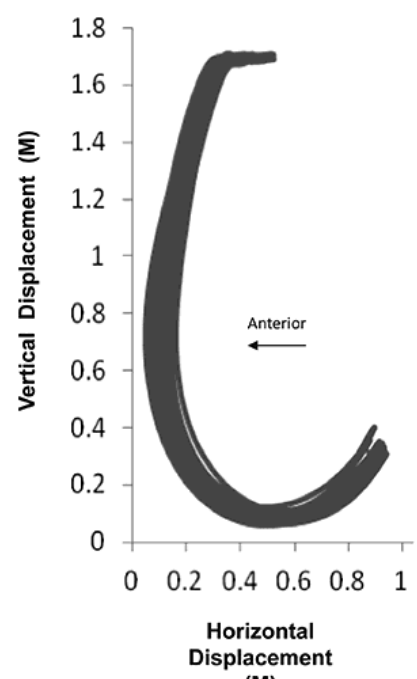

(M)
B

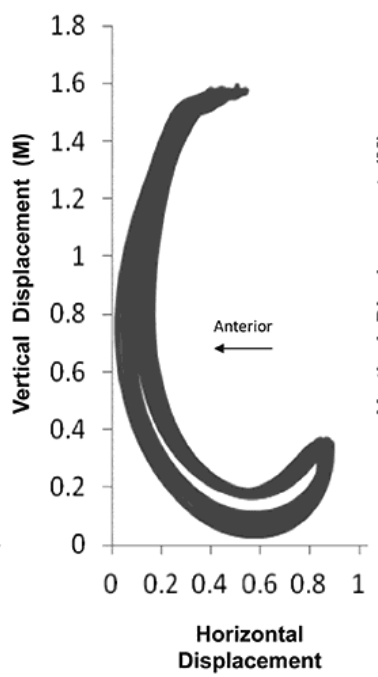

(M)
C

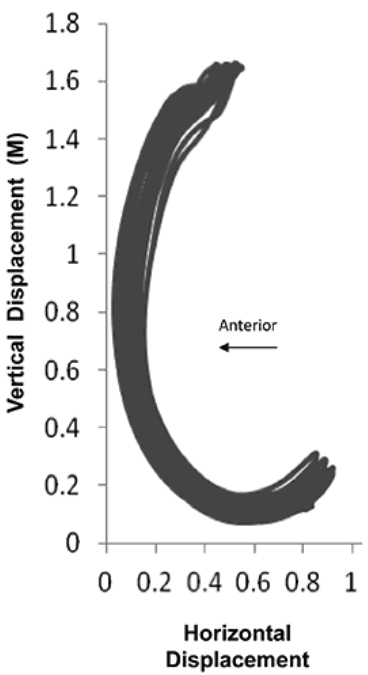

(M)

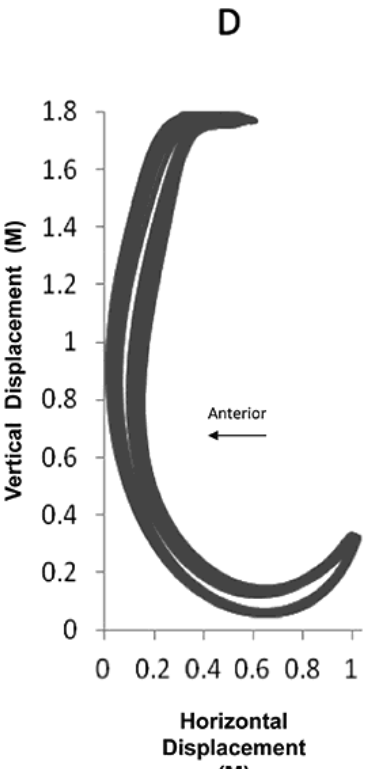

(M)

1
2
3

Figure 3. Sagittal plane kettlebell trajectory.

4

5

6

7

8

9

10

11

12

13

14 
A

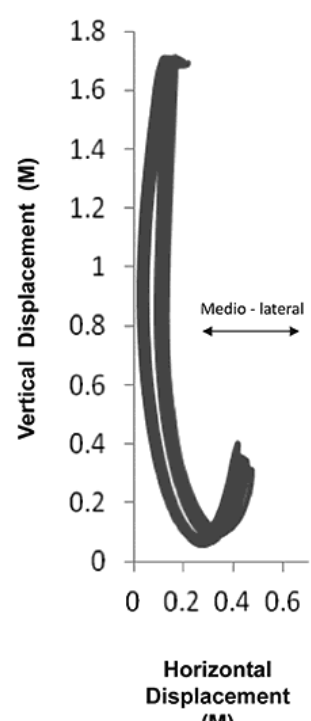

(M)
B

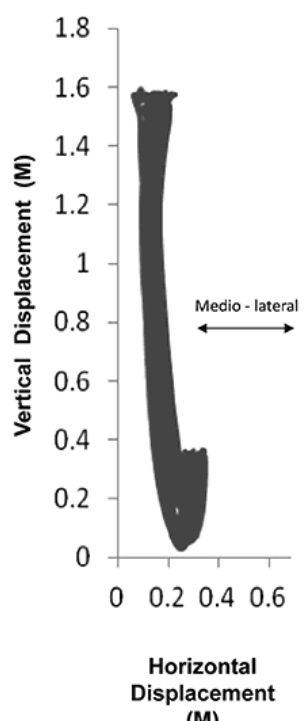

(M)
C

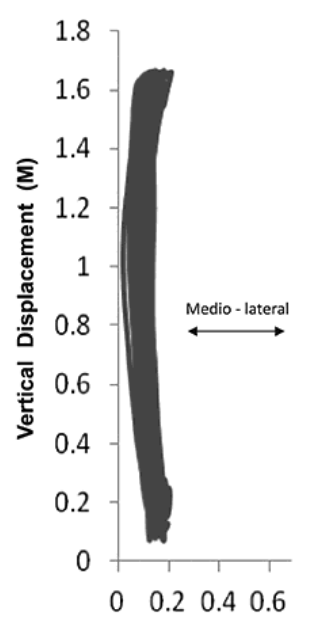

Horizontal

placement

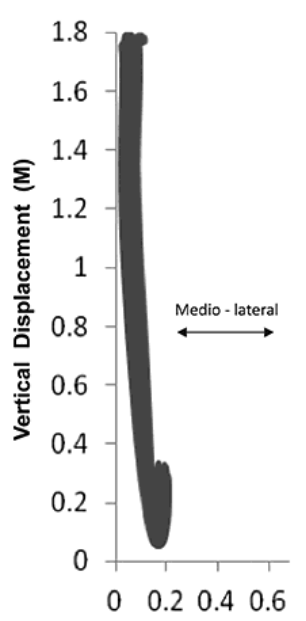

Horizontal

(M)

Figure 4. Frontal plane kettlebell trajectory.

3

4

5

6

7

8

9

10

11

12

13

14 


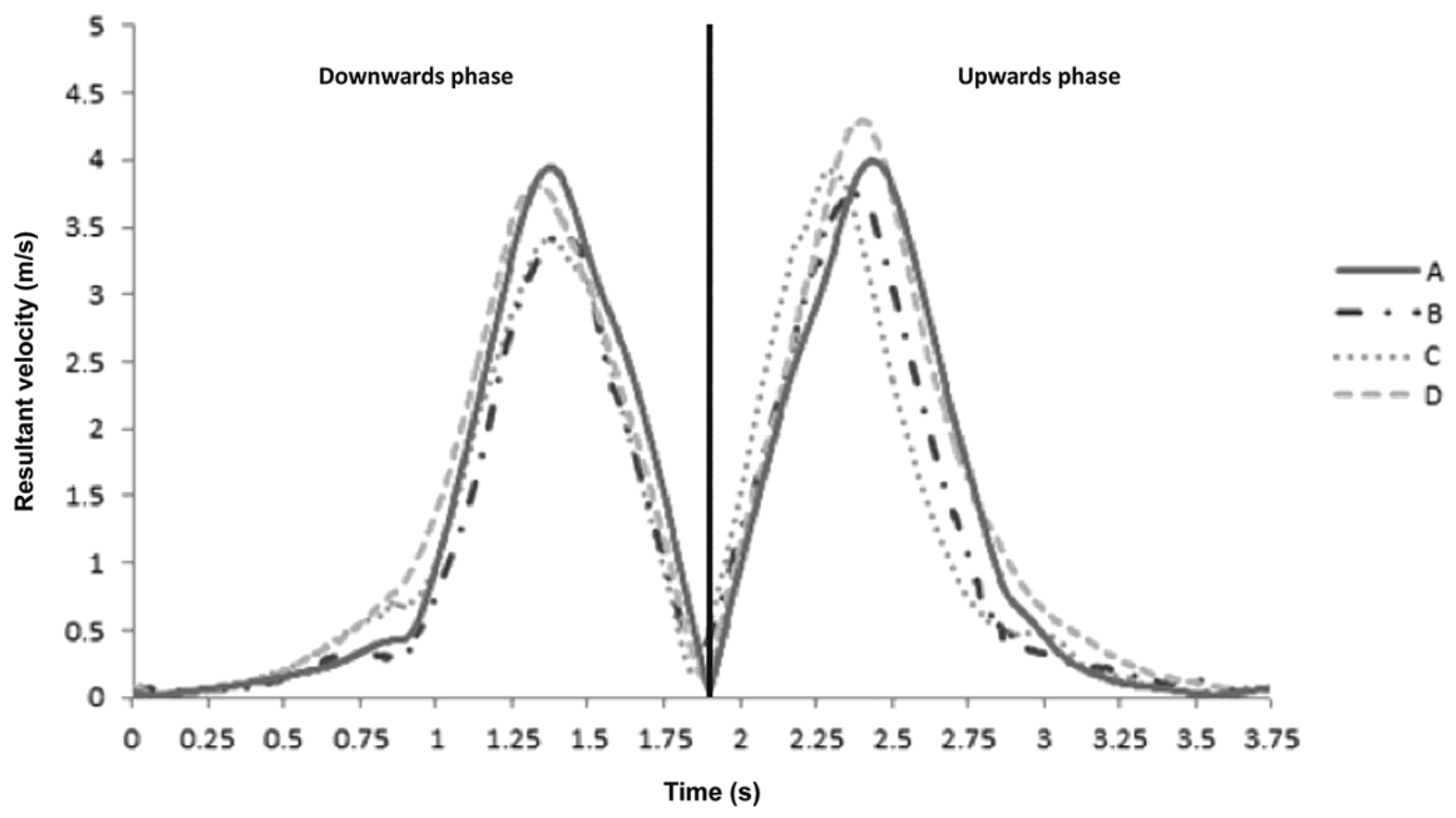

1

2 Figure 5. Typical KB resultant velocity-time curve for respective participants.

3

4

5

6

7

8

9

10

11

12

13

14

15 
TABLES

Table 1. Mean displacement ranges $(\mathrm{m})$ and ratios for respective participants

\begin{tabular}{|c|c|c|c|c|c|c|c|c|}
\hline & \multicolumn{2}{|c|}{ Lifter A } & \multicolumn{2}{|c|}{ Lifter B } & \multicolumn{2}{|c|}{ Lifter C } & \multicolumn{2}{|c|}{ Lifter D } \\
\hline & Up Phase & Down Phase & Up Phase & Down Phase & Up Phase & Down Phase & Up Phase & Down Pha \\
\hline $\mathrm{APV}$ & $0.67 \pm 0.02$ & $0.63 \pm 0.03$ & $0.66 \pm 0.02$ & $0.60 \pm 0.02$ & $0.60 \pm 0.02$ & $0.56 \pm 0.02$ & $0.66 \pm 0.02$ & $0.60 \pm 0.0$ \\
\hline MLR & $0.31 \pm 0.01$ & $0.26 \pm 0.02$ & $0.13 \pm 0.03$ & $0.13 \pm 0.03$ & $0.05 \pm 0.02$ & $0.06 \pm 0.02$ & $0.08 \pm 0.02$ & $0.07 \pm 0.0$ \\
\hline Vertical & $1.265 \pm 0.024$ & $1.265 \pm 0.024$ & $1.240 \pm 0.020$ & $1.240 \pm 0.020$ & $1.393 \pm 0.016$ & $1.393 \pm 0.016$ & $1.466 \pm 0.020$ & $1.466 \pm 0$. \\
\hline AP & $0.845 \pm 0.014$ & $0.798 \pm 0.027$ & $0.820 \pm 0.016$ & $0.744 \pm 0.025$ & $0.834 \pm 0.024$ & $0.783 \pm 0.035$ & $0.967 \pm 0.014$ & $0.877 \pm 0$. \\
\hline ML & $0.394 \pm 0.018$ & $0.329 \pm 0.031$ & $0.166 \pm 0.036$ & $0.165 \pm 0.34$ & $0.065 \pm 0.026$ & $0.080 \pm 0.035$ & $0.113 \pm 0.015$ & $0.103 \pm 0$. \\
\hline
\end{tabular}

All data are mean+standard deviations. APV: Anterior-Posterior to Vertical ratio, MLV: Medio-lateral to Vertical ratio. 
Table 2. Three dimensional ranges and effect size between the midpoint of the upwards and downwards phases (m).

\begin{tabular}{lcccc}
\hline & Lifter A & Lifter B & Lifter C & Lifter D \\
\hline AP & $0.049 \pm 0.023^{\star *}$ & $0.076 \pm 0.029^{\star \star}$ & $0.046 \pm 0.026^{\star *}$ & $0.090 \pm 0.017^{\star \star}$ \\
ES & 1.99 & 4.19 & 2.06 & 6.67 \\
ML & $0.070 \pm 0.020^{\star \star}$ & $0.018 \pm 0.013$ & $0.035 \pm 0.022$ & $0.014 \pm 0.008^{\star}$ \\
ES & 3.30 & 0.06 & 0.61 & 0.59 \\
Vertical & $0.022 \pm 0.015^{\star \star}$ & $0.062 \pm 0.030^{\star \star}$ & $0.034 \pm 0.020$ & $0.094 \pm 0.028^{\star \star}$ \\
ES & 1.29 & 3.45 & 0.51 & 5.34 \\
\hline
\end{tabular}

All data are mean + standard deviations. AP: Anterior-posterior, ML: Medio-lateral, *Significant difference in positions of upwards and downwards phases $(p<0.05)$, ** Significant difference in positions of upwards and downwards phases $(p<0.01)$. 
Table 3. Mean resultant velocity $\left(\mathrm{m} . \mathrm{s}^{-1}\right)$ of respective participants.

\begin{tabular}{ccccc}
\hline Phase & Lifter A & Lifter B & Lifter C & Lifter D \\
\hline Upwards & $3.95 \pm 0.4$ & $3.88 \pm 0.03$ & $4.03 \pm 0.13$ & $4.27 \pm 0.04$ \\
Downwards & $4.00 \pm 0.04$ & $3.52 \pm 0.05$ & $3.39 \pm 0.09$ & $3.83 \pm 0.02$ \\
ES & $-1.19^{\star \star}$ & $7.45^{\star \star}$ & $3.21^{\star \star}$ & $12.05^{\star \star}$ \\
\hline
\end{tabular}

All data are mean + standard deviations.

** Significant difference in resultant velocity of upwards and downwards phases $(p<$ 0.01). 
Table 3. Displacement range, radial error and absolute error for respective participants $(\mathrm{m})$

$\begin{array}{llll}\text { Lifter } \mathrm{A} & \text { Lifter } \mathrm{B} & \text { Lifter } \mathrm{C}\end{array}$

\begin{tabular}{lcccc}
\hline Phase & \multicolumn{3}{c}{ Anterior-Posterior } \\
& & & & \\
\hline End Back Swing & & & & \\
Range & $0.054 \pm 0.015$ & $0.033 \pm 0.012$ & $0.072 \pm 0.024$ & $0.044 \pm 0.012$ \\
AE & $0.012 \pm 0.09$ & $0.010 \pm 0.04$ & $0.019 \pm 0.013$ & $0.010 \pm 0.007$ \\
RE (APV) & $0.023 \pm 0.016$ & $0.023 \pm 0.09$ & $0.024 \pm 0.013$ & $0.019 \pm 0.012$ \\
Acceleration & & & & \\
Pull & & & & \\
Range & $0.032 \pm 0.009$ & $0.058 \pm 0.014$ & $0.066 \pm 0.023$ & $0.050 \pm 0.011$ \\
AE & $0.008 \pm 0.005$ & $0.010 \pm 0.010$ & $0.019 \pm 0.013$ & $0.008 \pm 0.008$ \\
RE (APV) & $0.015 \pm 0.008$ & $0.017 \pm 0.012$ & $0.028 \pm 0.014$ & $0.015 \pm 0.012$ \\
& & & & \\
Fixation & & & & \\
Range & $0.039 \pm 0.010$ & $0.105 \pm 0.028$ & $0.094 \pm 0.028$ & $0.067 \pm 0.021$ \\
AE & $0.007 \pm 0.006$ & $0.022 \pm 0.015$ & $0.022 \pm 0.017$ & $0.018 \pm 0.010$ \\
RE (APV) & $0.008 \pm 0.006$ & $0.023 \pm 0.016$ & $0.023 \pm 0.016$ & $0.018 \pm 0.010$ \\
& & & & \\
Re-gripping & & & & \\
Range & $0.105 \pm 0.026$ & $0.069 \pm 0.020$ & $0.090 \pm 0.023$ & $0.050 \pm 0.015$ \\
AE & $0.016 \pm 0.008$ & $0.016 \pm 0.011$ & $0.017 \pm 0.015$ & $0.011 \pm 0.008$ \\
RE (APV) & $0.022 \pm 0.020$ & $0.024 \pm 0.011$ & $0.032 \pm 0.027$ & $0.021 \pm 0.009$ \\
\hline Phase & & \multicolumn{2}{c}{ Medio-Lateral } & \\
\hline
\end{tabular}

\begin{tabular}{lllll}
\hline End Back Swing & & & & \\
Range & $0.062 \pm 0.016$ & $0.078 \pm 0.024$ & $0.051 \pm 0.018$ & $0.031 \pm 0.009$ \\
AE & $0.013 \pm 0.010$ & $0.019 \pm 0.014$ & $0.016 \pm 0.007$ & $0.007 \pm 0.005$ \\
RE (MLV) & $0.023 \pm 0.016$ & $0.023 \pm 0.009$ & $0.024 \pm 0.013$ & $0.019 \pm 0.012$
\end{tabular}

Acceleration

Pull

\begin{tabular}{lcccc} 
Range & $0.051 \pm 0.017$ & $0.062 \pm 0.016$ & $0.056 \pm 0.015$ & $0.046 \pm 0.012$ \\
AE & $0.015 \pm 0.008$ & $0.015 \pm 0.009$ & $0.011 \pm 0.009$ & $0.008 \pm 0.009$ \\
RE (MLV) & $0.015 \pm 0.008$ & $0.017 \pm 0.012$ & $0.028 \pm 0.014$ & $0.015 \pm 0.012$ \\
& & & & \\
Fixation & & & \\
Range & $0.062 \pm 0.020$ & $0.105 \pm 0.026$ & $0.090 \pm 0.025$ & $0.044 \pm 0.014$ \\
AE & $0.018 \pm 0.009$ & $0.019 \pm 0.017$ & $0.019 \pm 0.016$ & $0.012 \pm 0.008$ \\
RE (MLV) & $0.018 \pm 0.008$ & $0.020 \pm 0.016$ & $0.020 \pm 0.015$ & $0.012 \pm 0.007$ \\
& & & & \\
Re-gripping & & & & \\
Range & $0.097 \pm 0.027$ & $0.073 \pm 0.018$ & $0.108 \pm 0.030$ & $0.069 \pm 0.019$ \\
AE & $0.021 \pm 0.015$ & $0.014 \pm 0.012$ & $0.024 \pm 0.013$ & $0.015 \pm 0.011$ \\
RE (MLV) & $0.025 \pm 0.017$ & $0.023 \pm 0.012$ & $0.037 \pm 0.027$ & $0.023 \pm 0.009$ \\
\hline
\end{tabular}

Phase Vertical 


\begin{tabular}{|c|c|c|c|c|}
\hline $\begin{array}{l}\text { Range } \\
A E\end{array}$ & $0.018 \pm 0.015$ & $0.019 \pm 0.009$ & $0.012 \pm 0.009$ & $0.015 \pm 0.011$ \\
\hline \multicolumn{5}{|c|}{ Acceleration } \\
\hline Range & $0.044 \pm 0.014$ & $0.058 \pm 0.016$ & $0.069 \pm 0.022$ & $0.061 \pm 0.016$ \\
\hline$A E$ & $0.012 \pm 0.007$ & $0.011 \pm 0.008$ & $0.018 \pm 0.011$ & $0.012 \pm 0.011$ \\
\hline \multicolumn{5}{|l|}{ Fixation } \\
\hline Range & $0.004 \pm 0.001$ & $0.018 \pm 0.005$ & $0.019 \pm 0.005$ & $0.012 \pm 0.004$ \\
\hline$A E$ & $0.001 \pm 0.001$ & $0.004 \pm 0.003$ & $0.004 \pm 0.003$ & $0.003 \pm 0.002$ \\
\hline \multicolumn{5}{|c|}{ Re-gripping } \\
\hline Range & $0.055 \pm 0.017$ & $0.071 \pm 0.019$ & $0.144 \pm 0.036$ & $0.055 \pm 0.018$ \\
\hline$A E$ & $0.012 \pm 0.008$ & $0.015 \pm 0.007$ & $0.025 \pm 0.024$ & $0.015 \pm 0.009$ \\
\hline
\end{tabular}

All data are mean $\pm S D$, unless otherwise stated. $A E$ : absolute error. RE: radial error APV: Anterior-Posterior to Vertical ratio, MLV: Medio-lateral to Vertical ratio. 